EVS24

Stavanger, Norway, May 13-16, 2009

\title{
Analysis of Electric Vehicles on Utility Networks
}

\author{
K. Dyke, N. Schofield and M. Barnes \\ The University of Manchester, UK
}

\begin{abstract}
In order to satisfy the growing expectation for energy efficient eco-friendly transportation a number of vehicle concepts have emerged, including the hybrid electric vehicle (HEV) and battery electric vehicle (BEV). Vehicle dynamics necessitate careful sizing of onboard energy storage systems. As the penetration of electric vehicles, in both the public and private sector increases, the requirement to facilitate and utilize them becomes paramount. A particular class of vehicle, the plug-in hybrid-electric vehicle (PHEV) also poses a greater challenge to existing terrestrial based electrical supply systems. This paper of discusses the various future vehicle concepts and investigates the potential impact of PHEV's and BEV's fleets on the local electricity networks in the UK.
\end{abstract}

Keywords: V2G (vehicle to grid), PHEV (plug in hybrid electric vehicle), BEV (battery electric vehicle).

\section{Introduction}

As the realization that finite resources presently fulfil many of our energy needs there is a shift in both consumer expectations and industrial manufacture catalyzed by legislation to move towards 'more electric' systems. In such an environment it is envisaged that the existing electrical networks would be required to either support the additional loads of electric vehicles or be improved via infrastructure investment. The impact of such an increase in demand could become a sizable and significant portion of the electrical energy provided. For example, approximately $36 \%$ of the UK energy is consumed by the transportation market [1] and for this to move to the electrical networks would impose significant logistical issues in terms of generation transmission and distribution. The same is typical of most EU countries, indeed the transmission and distribution (T\&D) networks are already operating close to, or beyond, their rated capacity and failing more frequently to maintain supply due to demands beyond original design specifications. To satisfy the imminent fleets of PHEV's and maintain power quality additional power sources will be required on the network at a rate to match the market growth of more electric vehicles. This could be best achieved through a symbiotic relationship between electrical networks and electric vehicles.

In order to increase the security of transmission and distribution (T\&D) networks the installation of parallel lines or additional generation would typically be considered. The economies of scale provided by large power plants to produce cost effective electricity is best suited for base loads. T\&D networks typically have little energy storage, unless there is significant hydro capacity, leading to a just-in-time (JIT) management of electricity supply and demand which must be adequately matched to provide power within grid specifications and ensure an effective economic dispatch. However, implementing this approach is time consuming and not favoured due to financial commitment, and the environmental impact of such installations. Whilst there is a growing demand for increasing electrical security and 
power quality; the additional loads of a growing electric vehicle market and a trend towards increased electrical capacity could compromise an already fragile network and hinder the inception of PHEVs and BEVs.

An electric vehicle drive-train is designed for the highly dynamic power requirements typical of modern driving cycles. Produced in volume, PHEV's could provide a much needed localized energy storage element to electrical networks, for example, studies in the US have suggested that PHEV's could represent a quick-response electrical energy service amounting to $5-10 \%$ of US electric costs [2]. Thus, vehicles normally stationary for $96 \%$ of their daily use could provide the cost-effective and highly responsive networks required to achieve high power quality energy to local electrical grid [2]. It is important to consider the potential roles that PHEV and BEV's could play in strengthening existing network services and in reducing operational costs. The shift towards hybrid cars has already seen the largest market, the US, reach close to a million hybrids [3]. The integration and penetration of PHEV systems in the UK however, highlights two areas of concern: the ability of the network to meet standards utilizing load management; and the ability to accommodate loads which vary with geographical location.

This paper will discuss the various electric vehicle power-train concepts and assess their impact on residential electrical networks in the UK. Finally, the contribution to vehicle loads to distributed generation schemes will be discussed.

\section{Electric Vehicles}

\subsection{Power-train Definitions}

Urban driving is typified by high power discharge/charge rates for vehicle acceleration and braking demands respectively. This leads of over-sizing of the internal combustion engine (ICE) of conventional vehicles and hence their poor thermal efficiency and emissions when driving urban regimes. The progressive electrification of vehicle power-trains is an acknowledged technological development to mitigate these deficiencies. Indeed, the highly transient duty cycles typical or urban driving is ideally suited to electric vehicle power-trains where on-board energy sources can be combined to satisfy both the vehicle energy and power requirements [4]. The major technical drawback of all-electric power-trains is still the limitation of the on-board energy source, generally an electrochemical battery, and hence range. Hence, early commercial vehicles are hybrid technologies combining combustion engines and electrochemical batteries. However, with the development of more energy dense batteries, allelectric vehicles are contenders for many small to medium size urban vehicles.

For the purpose of this paper a number of vehicle definitions are proposed. The vehicles are varied to reflect the trend to increase the electrification of vehicles as they progress from ICE technologies (ICE) through to the hybrid-electric vehicles (HEV), plug-in hybrid electric vehicle (PHEV) and ultimately the all- or battery electric vehicle (BEV).

The UK Electric Vehicle Society (UKEVS) [5] defines the following vehicles:

- a Hybrid Electric Vehicle (HEV) is a vehicle whose primary ICE power-train is buffered by either an electrical or mechanical component. This includes the use of electrochemical batteries, super- or ultra-capacitors and electro-mechanical flywheels

- a Plug-in Hybrid Electric Vehicle (PHEV) is a HEV having a range of energy sources that can be coordinated or implemented independently to provide propulsion [6]. The UKEVS uses the IEEE definition that "a plugin hybrid electric vehicle is defined as any hybrid electric vehicle which contains at least: (i) a battery storage system of $4 \mathrm{kWh}$ or more, used to power the motion of the vehicle; (ii) a means of recharging that battery system from an external source of electricity; and (iii) and ability to drive at least 10 miles $(16.1 \mathrm{~km})$ in all-electric mode consuming no gasoline"

- a PHEV10 is defined as "any vehicle capable of repeating 5 complete cycles of the ECE drive cycle" - this is approximately 10 miles

- a PHEV34 is defined as a PHEV that can operate in all-electric mode for approximately 34 miles. This distance is further qualified by the ability to complete 5 repeated NEDC cycles. Note that this distance exceeds $50 \%$ of US vehicles which travel a distance of less than 29 miles per day [7], and 
- finally a BEV100 is defined as an all electric vehicle that is capable of driving repeated New European Driving Cycles (NEDC) normal (BEV100n) and enhanced (BEV100e) to a range equivalent to 100 miles.

In terms of more electrification of road transportation one could consider a vehicle electrification ratio (VER) as defined in Table 1. As the vehicle electrification ratio increases the demands placed on electrical networks will become greater - as the existing fossil fuel infrastructure is replaced by the electrical network. The network is further constrained by the increased loading and the varying geographical location of new vehicle loads.

Table 1: Vehicle Types and Vehicle Electrification Ratio (VER)

\begin{tabular}{cccccc}
\hline $\begin{array}{c}\text { Vehicle } \\
\text { Type }\end{array}$ & VER & $\begin{array}{c}\text { Electric Range } \\
(\mathrm{km})\end{array}$ & $\begin{array}{c}\text { Drive } \\
\text { (miles) }\end{array}$ & Rycle & Repeats \\
\hline ICE & 0.00 & - & - & - & - \\
HEV & 0.00 & - & - & - & - \\
PHEV10n & 0.10 & 16.0 & 10.0 & ECE & 16 \\
PHEV10e & 0.10 & 16.0 & 10.0 & ECE & 15 \\
PHEV34n & 0.34 & 55.1 & 34.4 & NEDCn & 5 \\
PHEV34e & 0.36 & 57.4 & 35.8 & NEDCe & 5 \\
BEV100n & 1.00 & 165.3 & 103.3 & NEDCn & 15 \\
BEV100e & 1.00 & 160.6 & 100.4 & NEDCe & 13.2 \\
\hline
\end{tabular}

Note: Driving range limit set to 100 miles.

\subsection{Future Electrochemical Energy Sources}

To-date, there are two main battery chemistries that show long term potential for electric vehicle power-train applications, the ZEBRA and Li-Ion based technologies. The ZEBRA technology is based on sodium nickel chloride chemistry. Its high energy density makes it a suitable choice for transport based applications [8]. Lithium-ion batteries are used extensively for portable systems from mobile phones to laptop computers [9] and are now being scaled for vehicle traction batteries.

\subsection{Vehicle Evaluation}

For the purpose of this study, the ZEBRA technology will be considered since the authors have application data available from a previous research project [10]. Here, simulation models of an all-electric vehicle were developed and test validated via a full vehicle test platform, thus this data will form a validation benchmark for the studies of Section IV. The vehicle was a $2500 \mathrm{~kg}$ urban taxi powered via two high peak power $(32 \mathrm{~kW})$, high temperature $\left(280^{\circ} \mathrm{C}\right)$, ZEBRA Zeb5 batteries. The prime mover for the taxi was a brushless permanent magnet (PM) machine with integrated gear reduction and differential drive to the vehicle back-axle. The PM machine was controlled via a three phase voltage source converter, the dc supply to which is provided by the traction batteries. Fig. 1 illustrates the vehicle on a rolling-road test facility (a), typical power data during NEDC loading and measured battery energy use (b) $[4,10,11]$.

The ZEBRA Zeb5 battery has a normal steady charging requirement between 3 and 10A over a 7 to 8 hour period which is ideal for overnight charging. However, fast charging from zero to $80 \%$ state-of-charge can be achieved within 70-80 minutes providing there is a suitable charger and electrical supply capability. Thus, opportunistic rapid charging between 30 and $60 \mathrm{~A}$ is a real possibility depending on the discharge rates prior to charging and if the electrical supply infrastructure exists.

\section{Residential Load Profiles}

\subsection{Load Profiles}

Presently domestic load scheduling is broken down over a twenty-four hour time period with seasonal changes and popular events given considerable attention. To evaluate the impact of vehicle electrification on existing residential loads, data from a European funded network [12] has been used. The network, titled "Residential Monitoring to Decrease Energy Use and Carbon Emissions in Europe (REMODECE)", proposes electrical load profiles and investigates the makeup of such profiles and variances across the 27 European member states. Data based on average consumption across the 27 European member states is referred to here as EU-27 and equates to an average residential energy requirement of 4670 $\mathrm{kWh} /$ year per household.

Fig. 2 illustrates the EU-27 residential load profile over a twenty-four hour period and the average power consumption (flat line) which is approximately $0.44 \mathrm{kWh} / \mathrm{h}$. From an ideal scheduling point of view, economic dispatch could be maximized if this consumption were highly predictable or better a constant demand. For this 
to be achieved some form of network storage would have to be present and have large penetration in residential areas. It has been suggested that this role could be satisfied by PHEV's [2] however, the sizing, penetration of vehicles and owner behaviour must be given consideration as discussed later.

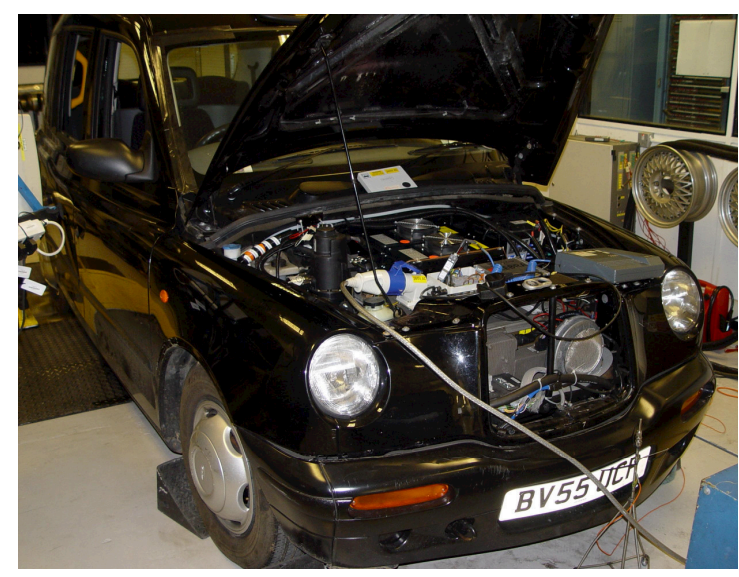

(a) Benchmark BEV, an all-electric taxi during rolling road testing.

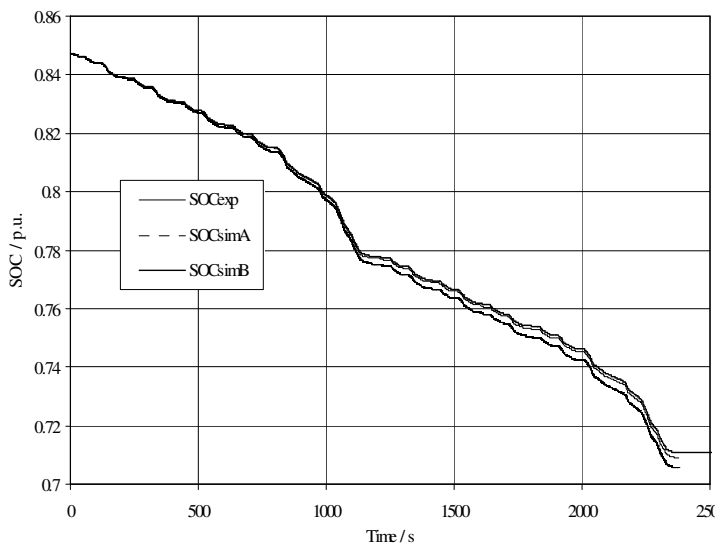

(b) Comparison of simulation model and measured state-of-charge (SOC) during NEDC range tests.

Fig. 1. BEV benchmark vehicle for model validation.

It is widely discussed that many electric vehicle systems could be charged during the evening hours utilizing spare thermal electrical generating capacity [13]. During the night electrical networks are typically lightly loaded and therefore electrical capacity must be reduced forcing the network to be operated off the design optimum for energy conversion, or generating plants have to be switched out. In order to reduce scheduling constraints network operators entice consumers, both commercial and domestic, to use electricity at night via financial incentives. In the UK, a domestic scheme offered for low priced electricity is known as the Economy 7 (E7) tariff. Here, electricity is billed at a lower value per $\mathrm{kWh}$ typically between the hours of 23:00 to 08:00. Note that times vary depending on region and in this study E7 will be assumed to be between 00:00 and 08:00.

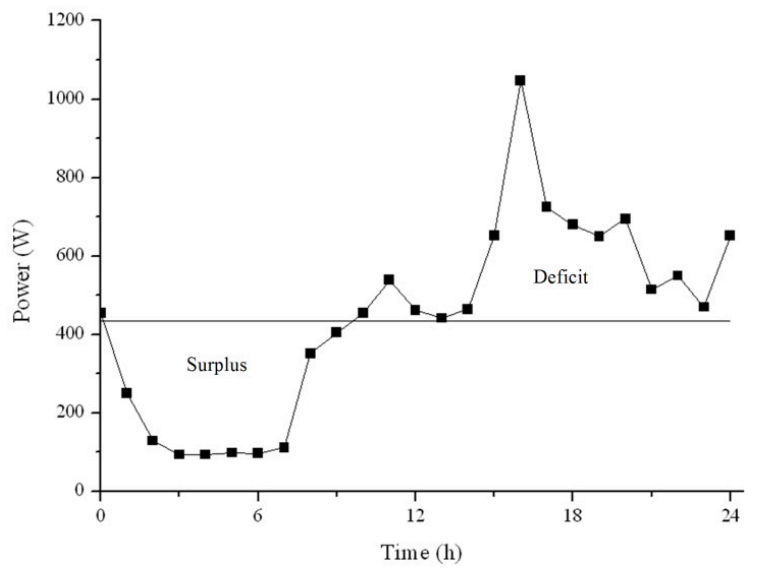

Fig. 2. Average residential load profile in the EU-27 member states.

From Fig.2. it can be seen that while there is the potential for spare capacity during the night, loads during the late afternoon demand considerable energy. This is typically due to cooking and heating demands such as microwaves, electric kettles and ovens etc. Local electrical storage could help to provide an element of load levelling if the capacity of such installations could be appropriately rated. If the residential load is less than the average highlighted in Fig. 2 it could be considered as a generating surplus while, conversely, it could be considered a deficit when the load is in excess of the average.

If this stored energy is to be provided via PHEV's, estimation of the rating of such storage for European networks requires an understanding of consumer driving behaviour. For the purpose of this study it is assumed that the PHEV will be available for three driving or usage behaviours:

- The first (and ideal scenario in terms of the utility), is that the PHEV onboard energy is always available. This is in fact not a viable consideration for vehicle operation, but 
bounds the energy calculation for the purpose of the study.

- The second scenario is defined 'family manager'; here the PHEV is unavailable between school hours, i.e. 9:00 till 15:00.

- The third most demanding scenario, in terms of recharging time availability, is that of the jobholder, where the storage is unavailable between working hours of 08:00 to 17:00.

Table 2 details the amount of energy required to supplement the EU-27 residential profile for the three driver behaviours scenarios considered. The ideal case quantifies the energy storage that would level an EU-27 profile. For the Family manager case, the E7 tariff could be utilized if no grid support was given during the day time. This would level the night profile, but increase the average. However, for the Job holder case, the recharging energy demand is over a shorter time thus increasing power demand. This would reduce the power demand variation over the twenty-four hour period but increase the E7 period beyond the EU-27 average.

Table 2: Domestic Energy Available

For Driver Behaviour

\begin{tabular}{cccc}
\hline $\begin{array}{c}\text { Hours } \\
\text { available }\end{array}$ & Scenario & \multicolumn{2}{c}{ Energy (MJ) } \\
& & Surplus & Deficit \\
\hline 24 & Ideal & 8.2 & 8.2 \\
20 & (i.e. domestic storage) & 7.5 & 7.8 \\
15 & Family Manger & 4.5 & 6.6 \\
\hline
\end{tabular}

\subsection{Types of Loads}

The majority of large residential electrical loads are static having fixed locations. These will be referred to as Fixed Location Loads (FLL) and include electrical loads such as: lighting, washing machines and home entertainment systems. Smaller electrical loads such as: laptops, mobiles and mp3 players; can be classed as Variable Location Loads (VLL). At present the ratio of fixed to variable location loads is heavily weighted towards fixed location loads [12] and therefore network operators are able to provide a service without considering variable location loads. However, this ratio will be inevitably become weighted towards variable location loads once PHEV loads begin to penetrate networks particularly if they can take advantage of multiple charging stations. This trend will be exacerbated by the increasing efficiencies of FLL such as improved home insulating materials and new lighting technologies. Thus, the impact of VLL will become more prominent on the network. Fast-response generation is already a necessary requirement for an electrical network [14] and a expensive service to sustain. Therefore, if EV's are to form part of the future electrical network, electrical energy management will become increasingly complex and consequently the requirement for fast-response generation will be increased. Thus, this new ratio of fixed and variable loads must be satisfied with flexible generation, the degree of which should be complementary to an electric vehicle presence.

\subsection{Comparison of UK and European Loads}

The residential electrical load profiles vary across the EU, for example, Eastern European countries tend to have loads primary made up of traditional domestic appliances, while loads in Western Europe have an increasing portion of high power entertainment systems: including set top boxes, DVD recorders and games consoles [12]. The variance in electrical load makeup and appliance efficiency ratings will require different dispatch strategies Europe-wide.

\section{Impact of EV's on Residential Supplies}

In order to evaluate the relationship between grid networks and electric vehicles, the energy requirements of each must be known. Now that the average EU-27 grid requirement is understood and the spare night-time capacity evening loads gauged, the implications for the supply of electric vehicle energy will be investigated for three vehicle platforms of varying degrees of electrification based on three Volkswagen AG (VW) products [15]:

- the Light Urban Vehicle (LUV) is based on the VW Polo, (mass $1500 \mathrm{~kg}$ )

- the Sport Utility Vehicle (SUV) is based on the VW Touareg (mass $2500 \mathrm{~kg}$ ), and

- the Light Goods Vehicle (LGV) is based on the VW Transporter, (mass $4500 \mathrm{~kg}$ ). 
Table 3: Vehicle Energy Requirements

\begin{tabular}{|c|c|c|c|c|c|}
\hline $\begin{array}{l}\text { Drive } \\
\text { Cycle }\end{array}$ & Metric & LUV & SUV & LGV & Units \\
\hline \multirow[t]{3}{*}{ PHEV10n } & $\begin{array}{l}\text { Energy 0\% } \\
\text { regen }\end{array}$ & 9.5 & 15.7 & 19.9 & MJ \\
\hline & $\begin{array}{c}\text { Energy } 50 \% \\
\text { regen }\end{array}$ & 8.6 & 14.4 & 18.1 & MJ \\
\hline & Peak Power & 15.8 & 26.6 & 34.1 & $\mathrm{~kW}$ \\
\hline \multirow[t]{3}{*}{ PHEV10e } & $\begin{array}{l}\text { Energy 0\% } \\
\text { regen }\end{array}$ & 9.7 & 15.1 & 18.7 & MJ \\
\hline & $\begin{array}{c}\text { Energy } 50 \% \\
\text { regen }\end{array}$ & 8.9 & 13.8 & 17.0 & MJ \\
\hline & Peak Power & 39.5 & 31.6 & 34.0 & $\mathrm{~kW}$ \\
\hline \multirow[t]{3}{*}{ PHEV34n } & $\begin{array}{l}\text { Energy 0\% } \\
\text { regen }\end{array}$ & 35.4 & 61.6 & 79.6 & MJ \\
\hline & $\begin{array}{c}\text { Energy } 50 \% \\
\text { regen }\end{array}$ & 33.2 & 58.5 & 75.2 & MJ \\
\hline & Peak Power & 39.7 & 72.8 & 55.1 & $\mathrm{~kW}$ \\
\hline \multirow[t]{3}{*}{ PHEV34e } & $\begin{array}{l}\text { Energy 0\% } \\
\text { regen }\end{array}$ & 36.5 & 62.1 & 79.7 & MJ \\
\hline & $\begin{array}{c}\text { Energy } 50 \% \\
\text { regen }\end{array}$ & 34.4 & 59.0 & 75.2 & MJ \\
\hline & Peak Power & 39.5 & 72.8 & 82.8 & $\mathrm{~kW}$ \\
\hline \multirow[t]{3}{*}{ BEV100n } & $\begin{array}{l}\text { Energy 0\% } \\
\text { regen }\end{array}$ & $\begin{array}{c}106 . \\
2\end{array}$ & $\begin{array}{c}184 . \\
8\end{array}$ & $\begin{array}{c}239 . \\
0\end{array}$ & MJ \\
\hline & $\begin{array}{c}\text { Energy } 50 \% \\
\text { regen }\end{array}$ & 99.7 & $\begin{array}{c}175 . \\
5\end{array}$ & $\begin{array}{c}225 \\
6\end{array}$ & MJ \\
\hline & Peak Power & 39.5 & 72.8 & 82.8 & $\mathrm{~kW}$ \\
\hline \multirow[t]{3}{*}{ BEV100e } & $\begin{array}{c}\text { Energy } 0 \% \\
\text { regen }\end{array}$ & $\begin{array}{c}102 . \\
3\end{array}$ & $\begin{array}{c}173 . \\
9\end{array}$ & $\begin{array}{c}223 . \\
1\end{array}$ & MJ \\
\hline & $\begin{array}{c}\text { Energy } 50 \% \\
\text { regen }\end{array}$ & 96.3 & $\begin{array}{c}165 . \\
2\end{array}$ & $\begin{array}{c}210 . \\
6\end{array}$ & MJ \\
\hline & Peak Power & 39.5 & 72.8 & 82.8 & $\mathrm{~kW}$ \\
\hline
\end{tabular}

\subsection{Vehicle Demands}

A vehicle model [16] developed in Mathworks ${ }^{\mathrm{TM}}$ Matlab® Simulink ${ }^{\circledR}$ is used to assess vehicle energy. The model uses vehicle specific parameters to define energy and power requirements. These are based on the three vehicles types LUV, SUV and LGV. Electrical power demanded by the traction drive is calculated using the mechanical output power and assuming a global motoring efficiency of $70 \%$ and regenerative braking efficiency of $50 \%$. Although the use of a fixed efficiency energy conversion parameter is a major simplification, the approximation provides a worst case energy benchmark and the vehicle mass the dominant factor. The vehicle energy requirement for each class is evaluated for the driving cycles presented in Section 3. The simulation results are summarized in Table 3 which lists the vehicle energy requirements for $0 \%$ and $50 \%$ regenerative braking and the peak power rating.

\subsection{PHEV Impact on EU-27Profile}

Fig. 3. illustrates the impact of a LUV-PHEV10 on the EU-27 average residential load profile of
Fig. 2 for Family manager usage. It can be seen that if the vehicle provides grid support $(+\mathrm{GS})$ during heavy domestic use then the EU-27 load profile can be smoothed considerably. In reality the afternoon peak load (not the averaged) could be in the region of 20A. However, this would still be within typical discharge limits of power dense batteries. Note, the PHEV10 drive cycle energy expenditure is not shown on Fig. 3 for clarity. It is envisaged that for this usage the PHEV would be driven between 9:00 to 15:00, i.e. during school or shopping journeys.

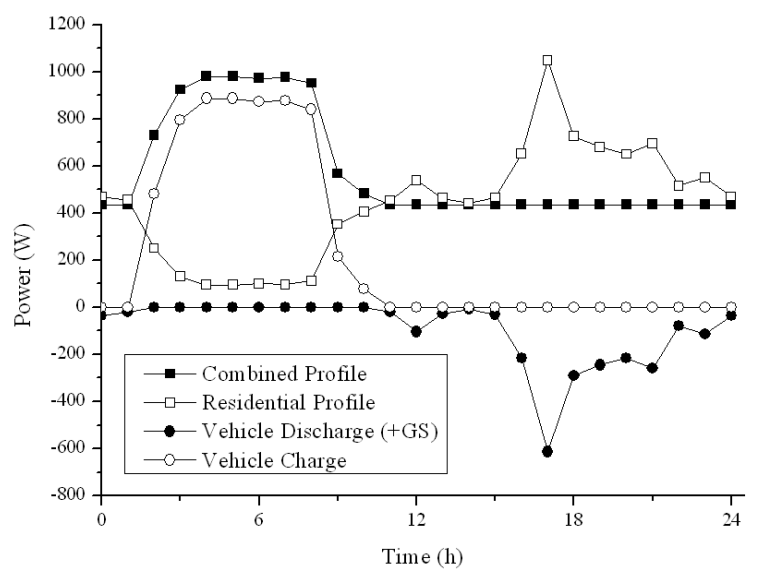

Fig. 3. The impact of a LUV-PHEV10 on the EU-27 average residential load profile.

The LUV-PHEV10e has an energy requirement (8.9MJ) similar to the present energy surplus found for an EU-27 average domestic profile (8.8MJ) PHEV10e could potentially provide the grid with a load levelling capability during E7 hours thus increasing economic dispatch efficiency. Fig. 4. illustrates the impact of charging an LUVPHEV10e on an EU-27 load profile. Results including grid support have assumed the PHEV has sufficient storage for both a PHEV10n journey and an additional $8.8 \mathrm{MJ}$ capacity. It can be seen, Fig. 5(a), that a LUV-PHEV10e with a reduced charging (RC) period and grid support (GS) capacity provides a highly predictable residential profile and constant daytime and evening load.

The SUV peak power requirement $(1.24 \mathrm{~kW})$ is $17.6 \%$ greater than the EU-27 peak, Fig. 5, although this could also be satisfied if there is sufficient network capacity for prolonged loads. Similarly, the LGV-PHEV10e with grid support requires a peak of $1.34 \mathrm{~kW}$ (not plotted). However, 
if the LGV does not offer grid support this peak can be reduced to $1.06 \mathrm{~kW}$. This results is less demand on electrical supply but impacts as creating larger variance in the residential load profile.

If the present EU-27 peak can be sustained over the entire twenty-four hour period then LUVPHEV10e and LUV-PHEV10n vehicles can be fully supported. SUV and LGV vehicles can be charged but only within the EU-27 peak if no grid support is provided. This results in a new load profile which would be difficult to predict and result in low economic dispatch efficiency increasing the demand for fast-response generation.

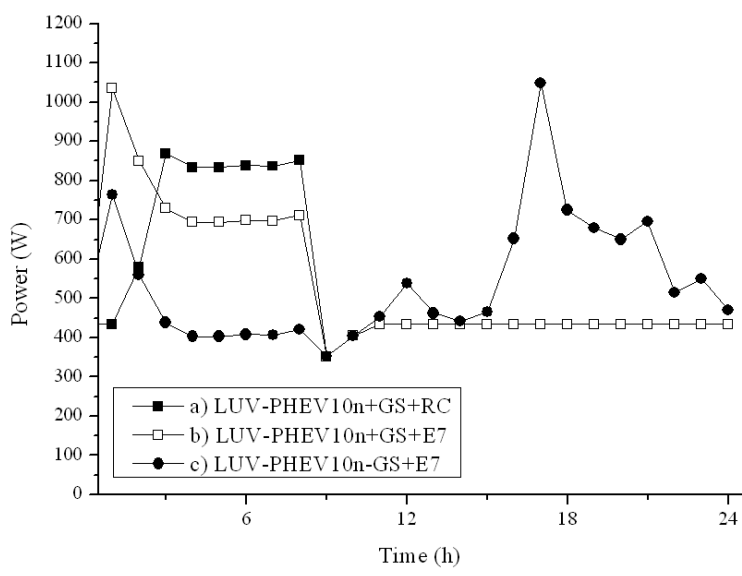

Fig. 4. LUV-PHEV10e, with Grid Support (+GS) without Grid Support (-GS) within E7 (+E7) and with reduced charging time $(\mathrm{RC})$.

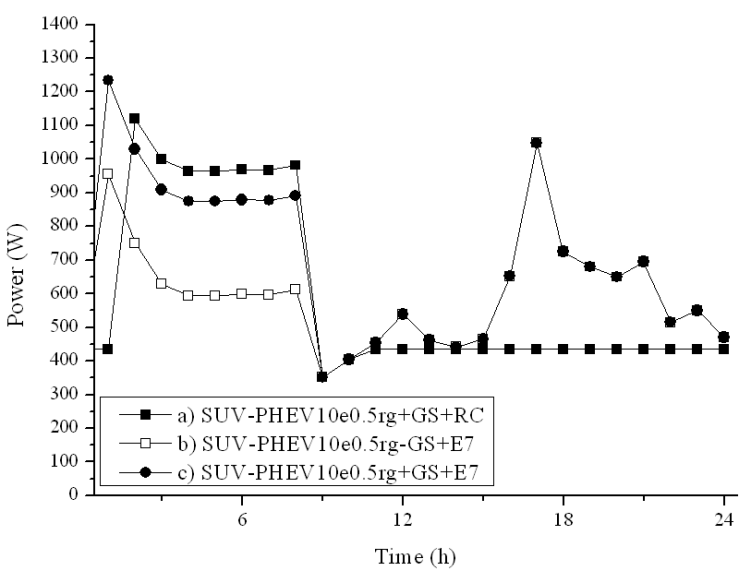

Fig. 5. SUV-PHEV10e, with Grid Support (+GS) without Grid Support (-GS) within E7 (+E7) and with reduced charging time $(\mathrm{RC})$.
Table VII shows the energy requirement for each of the three BEV vehicle types. If the LUVBEV100e was to be slowly charged over 14 hours, the current drawn would be marginally below 10 Amps. To quickly charge such vehicles, with preferred charge times of a few hours significant current must be drawn. While residential dwellings have supplies rated for operation close to $100 \mathrm{Amps}$, the local sub-station usually employs a significant diversity factor. Thus, the local network will require substantial infrastructure upgrades to support BEV related loads and this may not be possible without additional generation from existing infrastructure or in the residential locality, i.e. distributed generation.

Fig. 6 illustrates the resulting residential load profile if the electric vehicles provide grid support and are charged for a period 1 hour shorter than the typical E7 period. The charge time is shorten to lessen the impact on declining late night loads. Fig. 7 illustrates the new residential load demands for vehicles not providing grid support. It can be seen that resulting load profiles are varied and would prove difficult to effectively deploy generation.

\section{Conclusions}

A series of well defined electric vehicles have been used to derive the electrical energy storage requirements. These have then been applied to an EU residential load profile to evaluate the impact of such integration. It has been shown that low electrification vehicles such as large as the LGVPHEV10 is supported by the existing network.

Ensuring the domestic electrical networks can provide sustained power of approximately $3.5 \mathrm{~kW}$ allows support for SUV-PHEV34 vehicles. At $2 \mathrm{~kW}$ LUV-PHEV34 can be supported. However, if grid support is not offered by the PHEV's then load scheduling becomes increasingly complex and the requirement for fast-response generation is increased. If additional capacity can be maintained and PHEV provide grid support residential load profiles become very predictable and lend towards more effective economic dispatch with a environmental advantage. 


\section{Acknowledgments}

The authors acknowledge the UK Engineering and Physical Science Research Council (EPSRC) for provision of an Eng.D. award. The authors would also like to thank Frank Bryan for his assistance with Matlab ${ }^{\text {TM }}$ Simulink ${ }^{\circledR}$.

\section{References}

[1] BERR, "Digest of United Kingdom energy statistics 2008," D. f. B. E. R. Reform, Ed., 2008, p. 399 .

[2] W. Kempton and J. Tomic, "Vehicle-to-grid power fundamentals: Calculating capacity and net revenue," Journal of Power Sources, vol. 144, pp. 268-279, 2005.

[3] A. D. Vyas, "Argonne National Laboratory center for transportation Research, Analytical issues and Interim results.."

[4] N. Schofield, H. T. Yap, and C. M. Bingham, "Hybrid energy sources for electric and fuel cell vehicle propulsion," in Vehicle Power and Propulsion, 2005 IEEE Conference, 2005, pp. 522-529.

[5] UKEVS, "The UK Electric Vehicle Society (UKEVS)," www.ukevs.org, last visited 15 April 2009.

[6] Z. Rahman, K. L. Butler, and M. Ehsani, "Design studies of a series hybrid heavy-duty transit bus using V-ELPH 2.01," in Vehicular Technology Conference, 1999 IEEE 49th, 1999, pp. 22682272 vol.3.

[7] T. Markel, A. Brooker, J. Godner, M. O'Keefe, A. Simpson and M. Thornton, , "Plug-In Hybrid Vehicle Analysis" NREL/MP-540-40609, National Renewable Energy Laboratory, November 2006.

[8] H. Böhm and G. Beyermann, "ZEBRA batteries, enhanced power by doping," Journal of Power Sources, vol. 84, pp. 270-274, 1999.

[9] L. Yuang-Shung, W. Wei-Yen, and K. TsungYuan, "Soft Computing for Battery State-ofCharge (BSOC) Estimation in Battery String Systems," Industrial Electronics, IEEE Transactions on, vol. 55, pp. 229-239, 2008.

[10] N. Schofield, "ZESTFUL," UK Engineering and Physical Science Research Council (EPSRC) Grant No. GR/S81971/01.

[11] N. Schofield, H. T. Yap, and C. M. Bingham, "A $\mathrm{H} /$ sub 2/ PEM fuel cell and high energy dense battery hybrid energy source for an urban electric vehicle," in Electric Machines and Drives, 2005 IEEE International Conference on, 2005, pp. 1793-1800.

[12] R. n. Authors and Project no. EIE/05/124/SI2.419657, "Residential Monitoring to Decrease Energy Use and Carbon Emissions in Europe (REMODECE)." 
[13] A. Emadi, L. Young Joo, and K. Rajashekara, "Power Electronics and Motor Drives in Electric, Hybrid Electric, and Plug-In Hybrid Electric Vehicles," Industrial Electronics, IEEE Transactions on, vol. 55, pp. 2237-2245, 2008.

[14] Y. A. R. I. Mohamed and E. F. El-Saadany, "A Control Scheme for PWM Voltage-Source Distributed-Generation Inverters for Fast LoadVoltage Regulation and Effective Mitigation of Unbalanced Voltage Disturbances," Industrial Electronics, IEEE Transactions on, vol. 55, pp. 2072-2084, 2008.

[15] A.G.Volkswagen, "http://www.volkswagen.co.uk/," 2009/04/15.

[16] F. Bryan, D. R. Nuttall, A. J. Forsyth, C. Yonghua, J. Van Mierlo, and P. Lataire, "A Low-Cost Battery-Less Power Train for Small Fuel Cell Vehicle Applications," in Vehicle Power and Propulsion Conference, 2007. VPPC 2007. IEEE, 2007, pp. 43-49.

\section{Authors}

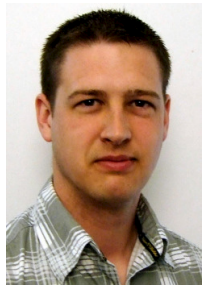

Kevin J. Dyke received the M.Eng degree from the University of Manchester Institute of Science and Technology (UMIST) in electrical and electronic engineering in 2005. He is presently on the Engineering Doctorate programme at The University of Manchester, UK. He is member of both the IET and IEEE.

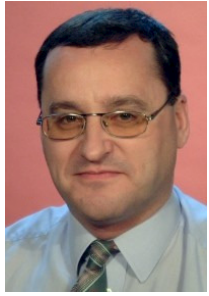

Nigel Schofield is a Lecturer in the Power Conversion Group in the School of Electrical and Electronic Engineering. He received the BEng and $\mathrm{PhD}$ degrees from the University of Sheffield, UK in 1990 and 1997 respectively. $\mathrm{He}$ is a Chartered Engineer in the UK and member of the IET and IEEE.

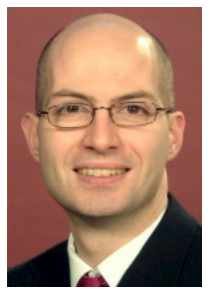

Mike Barnes is a senior lecturer in the power conversion group in the School of Electrical and Electronic Engineering. He received the BEng and $\mathrm{PhD}$ degrees from the University of Warwick, Coventry, UK in 1993 and 1998 respectively. $\mathrm{He}$ is an Associate Editor of the IEEE Transactions on Industry Applications. 